\title{
Unipolar Injection and Bipolar Transport in Electroluminescent Ru-centered Molecular Electronic Junctions
}

\section{Supporting Information}

Ushula M. Tefashe, Colin van Dyck, ${ }^{\dagger}$ Shailendra K. Saxena, Jean-Christophe Lacroix, ${ }^{\dagger}{ }^{\dagger}$ and Richard L. McCreery*

Department of Chemistry, University of Alberta, 11227 Saskatchewan Dr., Edmonton, Alberta T6G 2G2, Canada

† Department of Physics, University of Mons, 20, place du Parc, 7000 Mons, Belgium

\# University de Paris, ITODYS, CNRS UMR 7086, 15 rue J-A de Baif, F-75013 Paris, France

* corresponding author, mccreery@ualberta.ca, Tel.: 780-492-9594

Contents:

S1. Comparison of emission spectra to electrochemical example

S2. Comparison of $\mathrm{Ru}(\mathrm{bpy})_{3}$ and nitroazobenzene molecular junction emission

S3. $100 \mu$ sec Current $v$. time response for $\mathrm{Ru}(\mathrm{bpy})_{3}$ molecular junction

S4. Light emission transients for $\mathrm{Ru}(\mathrm{bpy})_{3}$ molecular junctions for $T=80$ to $320 \mathrm{~K}$

S5. Response curve for silicon detector

S6. Examples of reproducibility of IV curves and spectra.

S7. Table of molecular layer thickness by AFM 


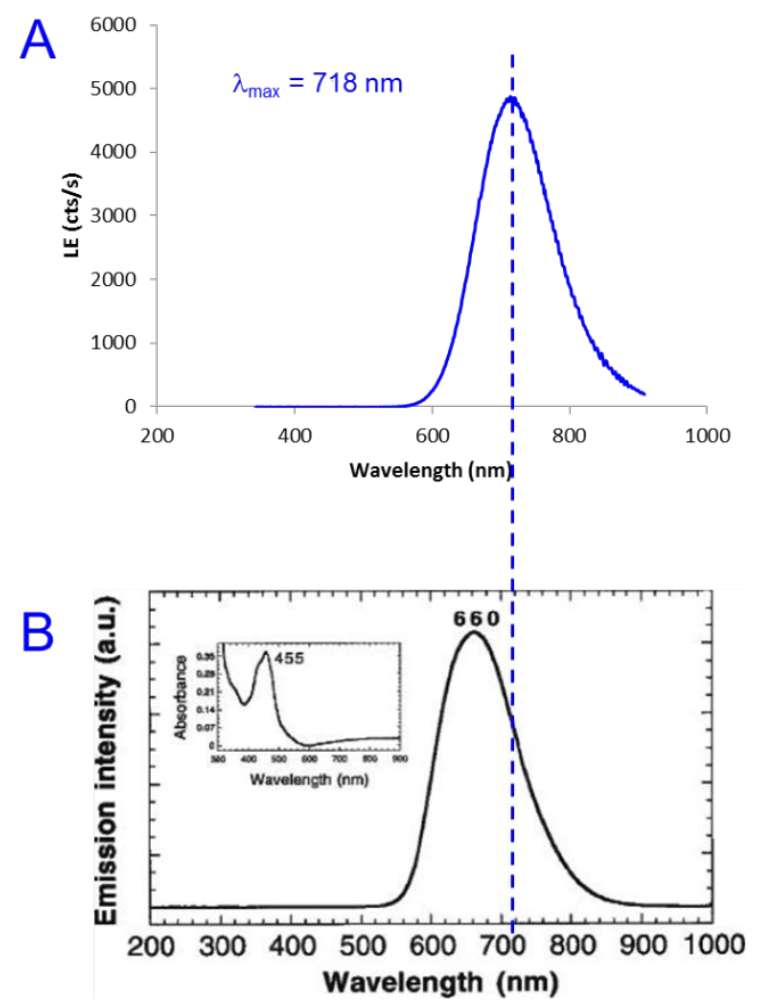

Figure S1. (A) Light emission spectra from $28 \mathrm{~nm} \mathrm{Ru}(\mathrm{bpy})_{3}$ junctions, (B) Emission spectra of a single layer ITO/Ru(bpy $)_{3}\left(\mathrm{ClO}_{4}\right)_{2} / \mathrm{Ga}: I n$ device (Bard et. al., J. Am. Chem. Soc. 2000, 122, 74267427). 

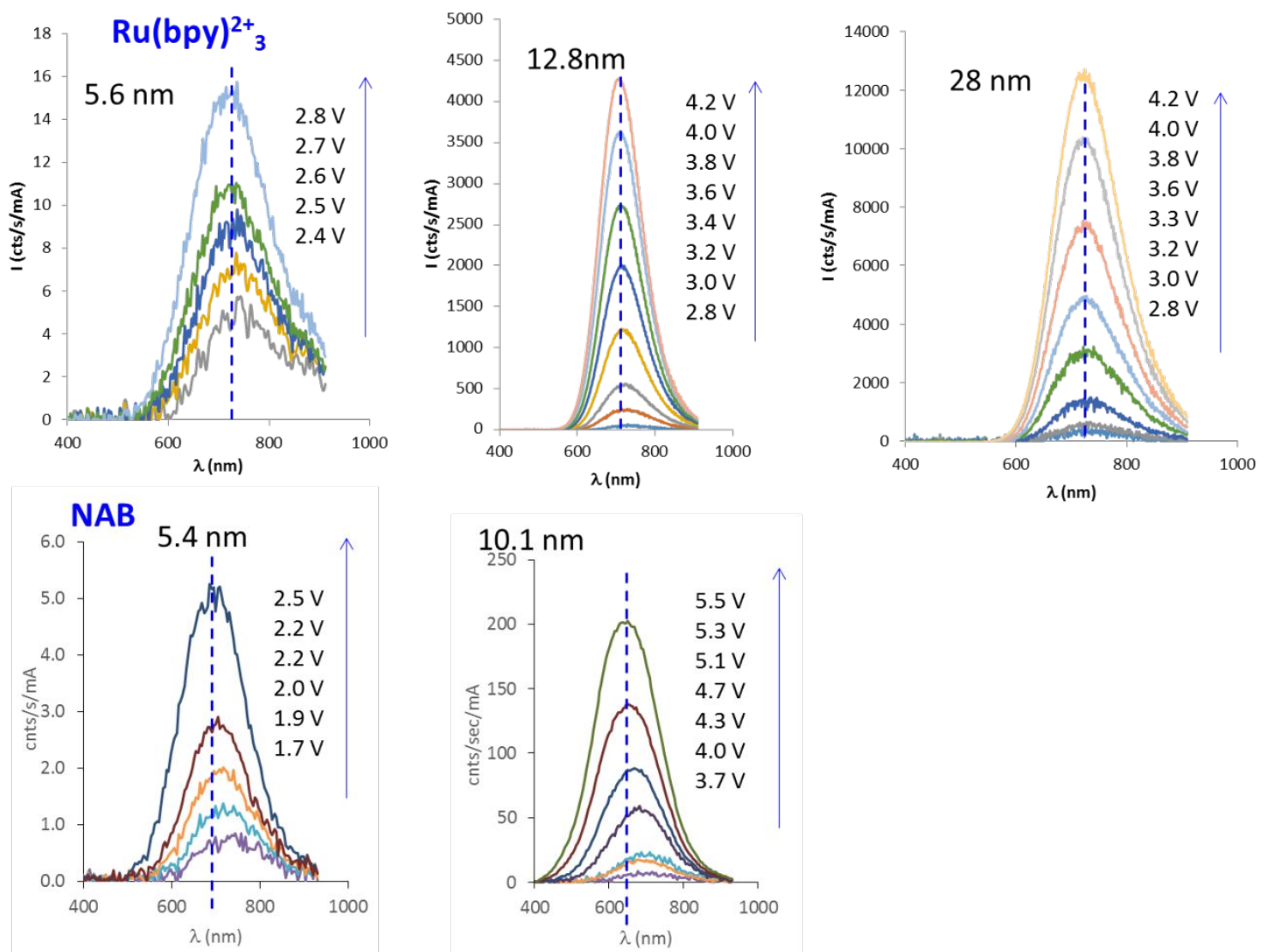

Figure S2. Additional uncorrected spectra of light emission for $5.6 \mathrm{~nm}, 12.8$, and $28 \mathrm{~nm}$

$\mathrm{Ru}(\text { bpy })_{3}$ junctions; and 5.4 and $10.1 \mathrm{~nm}$ NAB junctions. Applied DC bias for each thickness is indicated as inset. All curves are measured in positive polarity. Each spectrum was normalized to the junction current. 


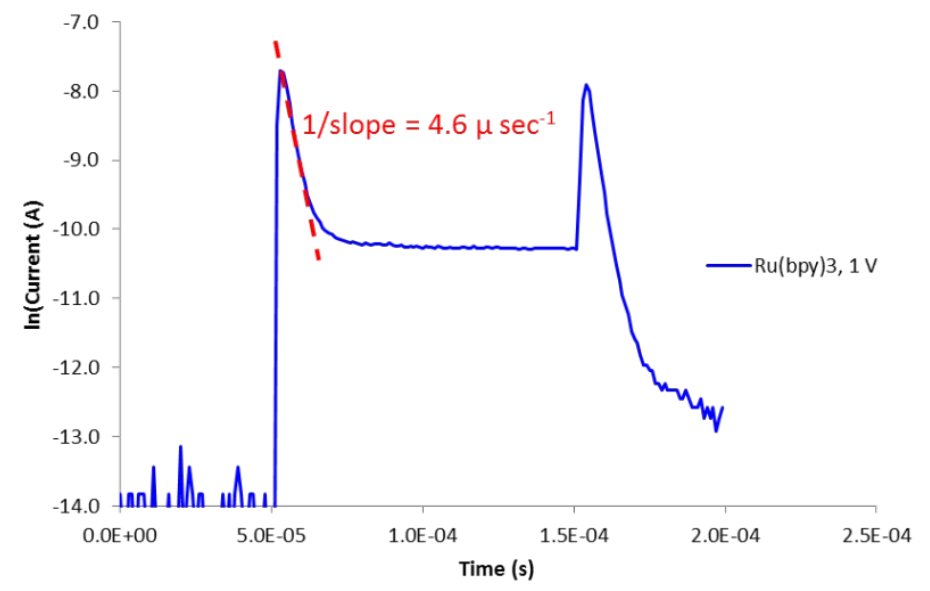

Figure S3. Current $v$ s time transients of a $\mathrm{eC} / \mathrm{Ru}(\mathrm{bpy})_{3} / \mathrm{eC}$ molecular junction with $d=12.8 \mathrm{~nm}$ showing charging current with an observed $\mathrm{RC}$ of $\sim 5 \mu$ sec.
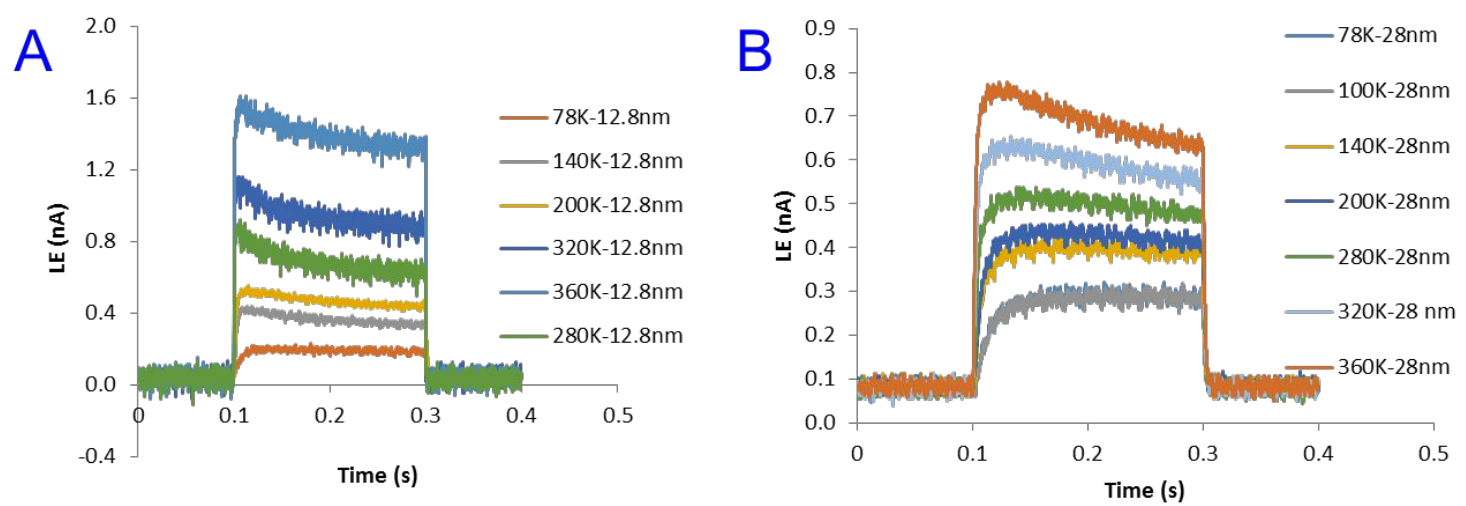

Figure S4. Additional light emission $v$ s time transients for $12.8 \mathrm{~nm}$ and $28 \mathrm{~nm} \mathrm{Ru}(\mathrm{bpy})_{3} \mathrm{MJ}$ for a $+3.0 \mathrm{~V}$ bias pulse at temperatures from $80 \mathrm{~K}$ to $320 \mathrm{~K}$ in vacuum. 


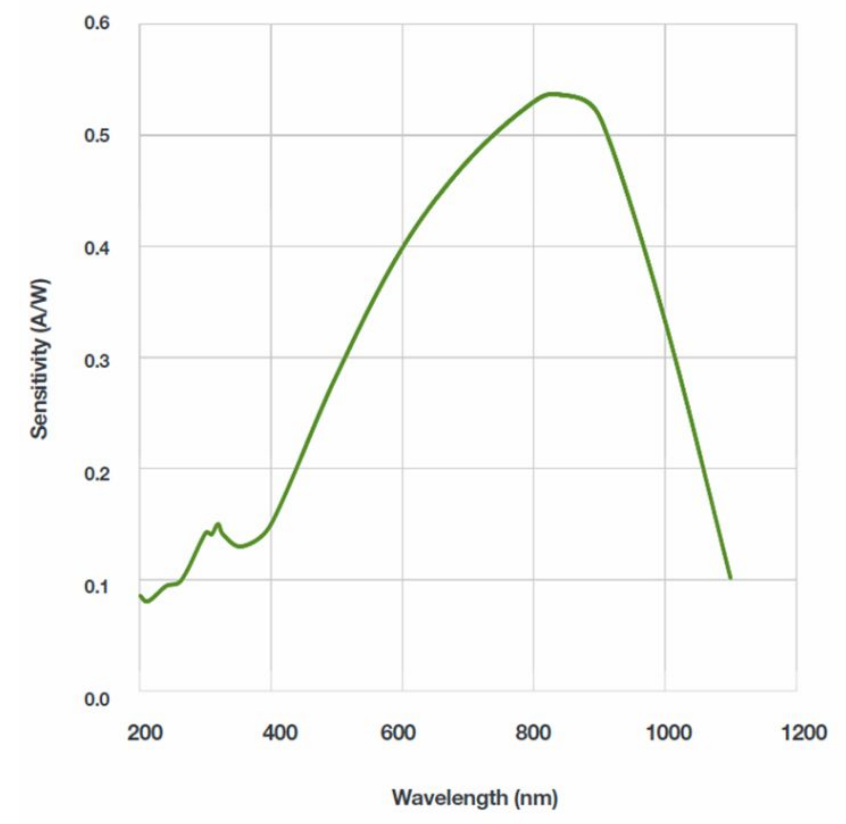

Figure S5. Spectral response of Andor Si detector (Andor SR-ASM-0046 UV enhanced Silicon Detector)

\section{Reproducibility of IV curves.}

Reported IV curves in figures are averages of at least four molecular junctions of each type and thickness. An example is shown in Figure S6 for four MJs from a given "chip" of 12 MJs used to construct Figure 1D in the main text. A more detailed analysis of reproducibility for $\mathrm{Ru}$ (bpy) ${ }_{3}$ MJs base on $\sim 80$ devices and nine different thicknesses is provided in the previous report, ${ }^{1}$ Figure 1C. 

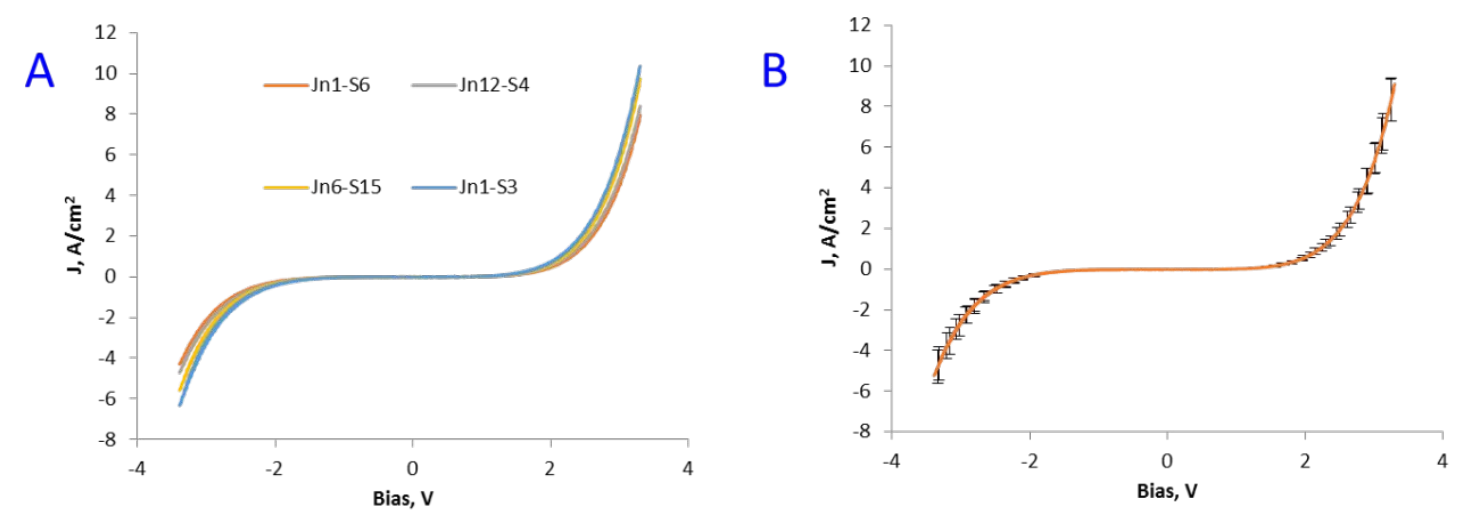

Figure S6. A. Overlay of four JV curves for Ru(bpy $)_{3} \operatorname{MJs}(d=12.8 \mathrm{~nm})$, and is typical of JV data for four thicknesses shown in Figure 1D of the main text. B. Average curve with error bars for the data of panel A.

Multiple LE spectra similar to Figure 1 and 2 of the main text and obtained from different junctions with the same $\mathrm{Ru}(\mathrm{bpy})_{3}$ thickness varied in intensity by less than $\sim 10 \%$. The reproducibility of multiple acquisitions of current transients such as those in Figure 3 and 4 of the main text was comparable to that of JV curves shown in Figure S6B, i.e. a relative standard deviation of $\sim 10-15 \%$. 


\section{S7. Table of molecular layer thickness by AFM}

Table S1. Electrochemical grafting parameters for $\mathrm{Ru}(\mathrm{bpy})_{3}$ on $\mathrm{Cr}_{4} / \mathrm{Au}_{30} / \mathrm{eC}_{10}$ : cyclic voltammograms (CV) scan range, number of CV scans, sweep rate, AFM thickness with standard deviation determined by "scratching" technique. ${ }^{2-3}$

\begin{tabular}{|c|c|c|c|c|}
\hline \multirow{3}{*}{ Molecules } & $\begin{array}{l}\text { CV scan range } \\
(\mathrm{V} \text { vs. Ag/Ag })\end{array}$ & $\begin{array}{l}\text { No. of CV } \\
\text { scans }\end{array}$ & Scan rate (mV/s) & $\begin{array}{l}\text { AFM "scratch" } \\
\text { thickness (nm) }\end{array}$ \\
\hline \multirow{5}{*}{$\mathrm{Ru}(\mathrm{bpy})_{3}$} & $0.4-(-0.8)$ & 9 & 100 & $5.6 \pm 0.4$ \\
\cline { 2 - 5 } & $0.4-(-1.0)$ & 10 & 100 & $8.3 \pm 0.6$ \\
\cline { 2 - 5 } & $0.4-(-1.25)$ & 10 & 100 & $12.8 \pm 0.7$ \\
\cline { 2 - 5 } & $0.4-(-1.4)$ & 9 & 100 & $20 \pm 1.4$ \\
\cline { 2 - 5 } & $0.4-(-1.6)$ & 6 & 100 & $28 \pm 2.2$ \\
\hline
\end{tabular}

1. Tefashe, U. M.; Nguyen, Q. V.; Morteza Najarian, A.; Lafolet, F.; Lacroix, J.-C.; McCreery, R. L., Orbital Control of Long-Range Transport in Conjugated and Metal-Centered Molecular Electronic Junctions. J. Phys. Chem. C 2018, 122, 29028-29038.

2. Sayed, S. Y.; Fereiro, J. A.; Yan, H.; McCreery, R. L.; Bergren, A. J., Charge transport in molecular electronic junctions: Compression of the molecular tunnel barrier in the strong coupling regime. Proc. Natl. Acad. Sci. U.S.A. 2012, 109, 11498-11503.

3. Anariba, F.; DuVall, S. H.; McCreery, R. L., Mono- and Multilayer Formation by Diazonium Reduction on Carbon Surfaces Monitored with Atomic Force Microscopy "Scratching". Analytical Chemistry 2003, 75, 3837-3844. 